\title{
Comparison of esophageal stent placement versus endoscopic incision method for treatment of refractory esophageal anastomotic stricture
}

\author{
Peiyao Wu, Fei Wang, Xiaochao Wu, Junjie Nie, Xianxiu Ge, Quanpeng Li, Jie Lin, Lin Miao \\ Institute of Digestive Endoscopy and Medical Center for Digestive Diseases, Second Affiliated Hospital of Nanjing Medical University, Nanjing \\ 210011, China \\ Contributions: (I) Conception and design: P Wu, J Lin, L, Miao; (II) Administrative support: L Miao; (III) Provision of study materials or patients: P \\ Wu, F Wang, X Wu, J Nie, X Ge; (IV) Collection and assembly of data: P Wu, J Lin, F Wang, X Wu; (V) Data analysis and interpretation: P Wu, J \\ Lin; (VI) Manuscript writing: All authors; (VII) Final approval of manuscript: All authors. \\ Correspondence to: Lin Miao, MD; Jie Lin, MD, Institute of Digestive Endoscopy and Medical Center for Digestive Diseases, Second Affiliated \\ Hospital of Nanjing Medical University, 121 Jiangjiayuan, Nanjing 210011, China. Email: linmiao@njmu.edu.cn; nylinjie@163.com.
}

\begin{abstract}
Background: Refractory esophageal anastomotic strictures are difficult to treat. Current treatments include esophageal stent placement (ESP) and the endoscopic incision method (EIM). This study was conducted to determine which treatment is better for patients with refractory esophageal anastomotic stricture.

Methods: This study retrospectively collected data of patients with refractory esophageal anastomotic stricture who underwent ESP or EIM between January 2012 and June 2018. Dysphagia scores before and after the procedure were recorded in both groups. The duration of relief during the follow-up period was recorded.

Results: Fifty patients were enrolled in this study, including 32 patients who underwent ESP and 18 who underwent EIM. Patients in the ESP group had a markedly larger diameter of dilatation than those in the EIM group $(19.9 \pm 1.8$ versus $11.0 \pm 1.9 \mathrm{~mm}$, respectively; $\mathrm{P}<0.001)$. However, the dysphagia score improved by $1.0 \pm 0.0$ point in the ESP group and by $1.4 \pm 0.5$ points in the EIM group $(\mathrm{P}<0.001)$. Nearly $70 \%$ of patients in the ESP group maintained lumen patency at 12 months. In contrast, only $50 \%$ of patients in the EIM group had persistent relief of stricture symptoms at 6 months and only $20 \%$ had relief at 12 months. Five patients had slight bleeding; none required blood transfusion. Thirteen patients in the ESP group had slight chest pain; seven of these required administration of a painkiller.

Conclusions: EIM can rapidly relieve the symptoms of esophageal anastomotic stricture but ESP provides longer duration of relief. Both procedures are safe for patients with refractory esophageal anastomotic stricture.
\end{abstract}

Keywords: Refractory esophageal anastomotic stricture; esophageal stent placement (ESP); endoscopic incision method (EIM); efficiency; safety

Submitted Mar 25, 2019. Accepted for publication Aug 29, 2019.

doi: 10.21037/apm.2019.09.07

View this article at: http://dx.doi.org/10.21037/apm.2019.09.07

\section{Introduction}

Reported 5-year survival rates for esophageal cancer range from $15 \%$ to $20 \%$ and over $50 \%$ of patients are diagnosed with advanced-stage disease (1-3). Surgical resection of the lesion segment is the preferred treatment for esophageal cancer. However, many adverse events occur after surgical treatment, one of the most common of which is anastomotic stricture. The reported incidence of postoperative anastomotic stricture is $5 \%$ to $46 \%$; dysphagia is the most frequent symptom of affected patients (4-6). Simple endoscopic bougie or balloon dilatation is the most common treatment for anastomotic strictures. However, 
some refractory strictures do not respond to repeated dilatation and remain difficult to treat. Relieving refractory esophageal stricture to improve prognosis and quality of life is a challenging problem. Present solutions include two main procedures: esophageal stent placement (ESP) and the endoscopic incision method (EIM) (7-9).

Three types of esophageal stent are available: uncovered, partially covered and fully covered. Among these, uncovered and partially covered stents have a lower migration rate; however, these types are hard to remove, which may result in massive hemorrhage. Covered stents have a high migration rate but are easy to remove. All three types can provide immediate resolution of dysphagia symptoms. The fully covered esophageal stent is the most frequently used. However, it was reported that $30 \%$ to $60 \%$ of strictures will recur within 1 year of treatment (10).

EIM is a novel technique developed in recent years. EIM was first used to treat recurrent Schatzki rings $(11,12)$. Recently, the technique has been used as an alternative to balloon dilatation to treat refractory esophageal anastomotic strictures $(13,14)$. EIM is usually performed with an insulated-tip (IT) knife to excise the fibrotic stricture tissue. Several studies have reported satisfactory effects of EIM in the treatment of refractory esophageal stricture (13-16). The technique is more effective than endoscopic bougie and balloon dilatation for strictures narrower than $1 \mathrm{~cm}(17)$.

To our knowledge, no study has compared the efficacy of ESP with that of EIM in the treatment of refractory esophageal anastomotic stricture. This study was conducted to determine which treatment is better for resolving dysphagia symptoms and improving quality of life in patients with refractory esophageal anastomotic stricture.

\section{Methods}

\section{Study population}

This was a retrospective cohort study of patients with refractory esophageal anastomotic stricture admitted to the Second Affiliated Hospital of Nanjing Medical University between January 2012 and June 2018. All enrolled patients were diagnosed with refractory esophageal anastomotic stricture on the basis of endoscopy examination. Refractory esophageal anastomotic stricture was defined as stricture that did not improve to a diameter larger than $14 \mathrm{~mm}$ after three or more sessions of endoscopic balloon dilatation with an interval of at least 1 week between treatments $(13,18)$. This study was performed in compliance with the ethical principles of the Declaration of Helsinki and was approved by the Ethics Committee of Second Affiliated Hospital of Nanjing Medical University [(2019)KY085]. Because of the retrospective nature of the study, written informed consent was not obtained from the patients.

For those who were admitted to our hospital multiple times, only the first admission was recorded. Patients younger than 18 years or older than 80 years, those not diagnosed with esophageal cancer, those diagnosed with esophageal stricture and fistulae, those who did not undergo surgical treatment and those who underwent endoscopic submucosal dissection were excluded.

The collected parameters were as follows: age, sex, body mass index (BMI), serum albumin level, comorbidities, histology type, time between surgery and development of anastomotic stricture, stricture location, length and diameter of anastomotic stricture and dysphagia score. The outcomes in our study included diameter of the anastomotic stricture and dysphagia score after the procedure. Enrolled patients were followed up until June 2018; readmissions for dysphagia were recorded.

\section{Stents and stent placement procedure}

Partially covered self-expanding metal stents were used in the ESP group. All procedures were performed under sedation. The stent was made of a silicone-covered midsection with a diameter of 18 or $20 \mathrm{~mm}$ and double flares (proximal and distal) with a diameter of 24 to $32 \mathrm{~mm}$. The available lengths of stents ranged from 60 to $150 \mathrm{~mm}$ $(60,80,90,100,120,140,150 \mathrm{~mm})$. Stents were placed under fluoroscopic guidance. Patients were monitored for acute adverse events within 2 hours after the procedure. Correct stent positioning was evaluated endoscopically and/ or radiographically. Stents were usually removed within 4 to 12 weeks after placement.

\section{EIM procedure}

EIM procedures were all performed under direct visualization via single-channel endoscopy. EIM was performed as described previously $(9,13)$. First, the stricture tissues were incised with an IT knife along a virtual line connecting the esophageal lumen on the oral side with the lumen on the caudal side of the stricture. The incision area was then excised and observed for perforation and hemorrhage. Patients were monitored for acute adverse events for 2 hours after the procedure. 
Table 1 Demographics of included patients

\begin{tabular}{|c|c|c|c|}
\hline \multirow{2}{*}{$\begin{array}{l}\text { Variables } \\
\text { Case }\end{array}$} & \multicolumn{3}{|c|}{ Stent group Incision group $P$ value } \\
\hline & 32 & 18 & \\
\hline Age, years & $66.1 \pm 9.1$ & $65.4 \pm 5.4$ & 0.772 \\
\hline Gender (\%) & & & 0.033 \\
\hline Male & $28(87.5)$ & $11(61.1)$ & \\
\hline Female & $4(12.5)$ & 7 (38.9) & \\
\hline $\mathrm{BMI}$ & $17.9 \pm 1.9$ & $20.1 \pm 1.6$ & $<0.001$ \\
\hline Albumin, g/L & $36.6 \pm 5.5$ & $42.5 \pm 2.4$ & $<0.001$ \\
\hline \multicolumn{4}{|l|}{ Comorbidity (\%) } \\
\hline Diabetes mellitus & $3(9.4)$ & $1(5.6)$ & 1.000 \\
\hline Hypertension & $7(21.9)$ & $1(5.6)$ & 0.231 \\
\hline Chronic heart disease & $4(12.5)$ & $0(0)$ & 0.283 \\
\hline Histology (\%) & & & 0.723 \\
\hline Squamous cell carcinoma & $22(68.8)$ & $14(77.8)$ & \\
\hline Adenocarcinoma & $10(31.3)$ & $4(22.2)$ & \\
\hline Stricture location (\%) & & & 0.093 \\
\hline Upper esophagus & $8(25.0)$ & $8(44.4)$ & \\
\hline Mid esophagus & $12(37.5)$ & $8(44.4)$ & \\
\hline Lower esophagus & $12(37.5)$ & $2(11.1)$ & \\
\hline Stricture length, $\mathrm{cm}$ & $3.6 \pm 2.3$ & $2.6 \pm 1.2$ & 0.069 \\
\hline Diameter of stricture, $\mathrm{mm}$ & $3.5 \pm 1.7$ & $4.4 \pm 1.0$ & 0.049 \\
\hline Follow-up period & $28.0 \pm 16.2$ & $13.9 \pm 5.9$ & $<0.001$ \\
\hline
\end{tabular}

\section{Evaluation of dysphagia before and after the procedure}

The grading system for dysphagia before and after the procedure was based on the criteria previously reported in other studies: 0 , normal swallowing; 1 , able to swallow some solid food; 2, able to swallow semi-liquid food; 3, able to swallow liquids only; and 4, absolute dysphagia.

\section{Statistical analysis}

STATA (version 12.0) was used for all data analysis. Categorical variables were reported as percentages; continuous variables were reported as means with standard deviations. All continuous variables were analyzed with 2 -tailed t tests; categorical variables were analyzed with $\chi^{2}$ tests. The level of significance was set at the conventional level of $\alpha=0.05$. All $P$ values were 2 -sided; values $<0.05$ were considered statistically significant.

\section{Results}

\section{Patient demographics}

Fifty patients who met inclusion and exclusion criteria were enrolled in this study, including 32 patients who underwent ESP and 18 who underwent EIM. Patient demographics are listed in Table 1. The mean age was $66.1 \pm 9.1$ years in the ESP group and $65.4 \pm 5.4$ years in the EIM group. The ESP group included $28(87.5 \%)$ men and $4(12.5 \%)$ women; the EIM group included $11(61.1 \%)$ men and 7 (38.9\%) women. The BMI at admission was significantly different between the groups $\left(17.9 \pm 1.9 \mathrm{~kg} / \mathrm{m}^{2}\right.$ in ESP group versus $20.1 \pm 1.6$ $\mathrm{kg} / \mathrm{m}^{2}$ in EIM group, $\left.\mathrm{P}<0.001\right)$. Serum albumin level at admission was higher in the EIM group than in the ESP group (42.5 \pm 2.4 versus $36.6 \pm 5.5 \mathrm{~g} / \mathrm{L}$, respectively; $\mathrm{P}<0.001$ ). More patients in the ESP group had been diagnosed with diabetes mellitus, hypertension and chronic heart disease, but the difference between groups was not significant. The primary disease was esophageal carcinoma, with squamous cell carcinoma the most common type in both groups. The strictures in all patients occurred after esophagectomy. In the ESP group, eight patients had upper esophageal strictures, 12 had mid-esophageal strictures and 12 had lower esophageal strictures. In the EIM group, the number of patients with upper, mid- and lower esophageal strictures were eight, eight and two, respectively. The length of stricture in the ESP group was $3.6 \pm 2.3 \mathrm{~cm}$, whereas that in the EIM group was $2.6 \pm 1.2 \mathrm{~cm}$. The diameter of strictures in the ESP group was much smaller than that in the EIM group $(3.5 \pm 1.7$ versus $4.4 \pm 1.0 \mathrm{~mm}$, respectively; $\mathrm{P}=0.049)$. The follow-up period in the ESP group was 28.0 \pm 16.2 months; that in the EIM group was $8.9 \pm 5.9$ months.

\section{Efficacy of procedure}

The dysphagia scores of patients at admission and after the procedures are shown in Table 2. Patients in the ESP group had a higher dysphagia score at admission than those in the EIM group $(3.3 \pm 0.5$ versus $2.9 \pm 0.4$ points, respectively; $\mathrm{P}=0.008)$. After treatment, the dysphagia scores in the ESP group remained higher than those in the EIM group $(2.3 \pm 0.5$ versus $1.6 \pm 0.8$ points, respectively; $\mathrm{P}<0.001)$. Dysphagia scores in the ESP group improved by $1.0 \pm 0.0$ point whereas those in the EIM group improved by $1.4 \pm 0.5$ points $(\mathrm{P}<0.001)$. Details of the improvement in dysphagia scores 
Table 2 Efficacy of procedures

\begin{tabular}{lccc}
\hline Variables & $\begin{array}{l}\text { Stent group } \\
(32 \text { records })\end{array}$ & $\begin{array}{c}\text { Incision group } \\
(\mathrm{n}=18 \text { records })\end{array}$ & $\mathrm{P}$ value \\
\hline $\begin{array}{l}\text { Dysphagia score at } \\
\text { admission }\end{array}$ & $3.3 \pm 0.5$ & $2.9 \pm 0.4$ & 0.008 \\
$\begin{array}{l}\text { Dysphagia score at } \\
\text { discharge }\end{array}$ & $2.3 \pm 0.5$ & $1.6 \pm 0.8$ & $<0.001$ \\
$\begin{array}{l}\text { Dysphagia score of } \\
\text { improvement }\end{array}$ & $1.0 \pm 0.0$ & $1.4 \pm 0.5$ & $<0.001$ \\
$\begin{array}{l}\text { Diameter of dilatation, } \\
\text { mm }\end{array}$ & $19.9 \pm 1.8$ & $11.0 \pm 1.9$ & $<0.001$ \\
\hline
\end{tabular}

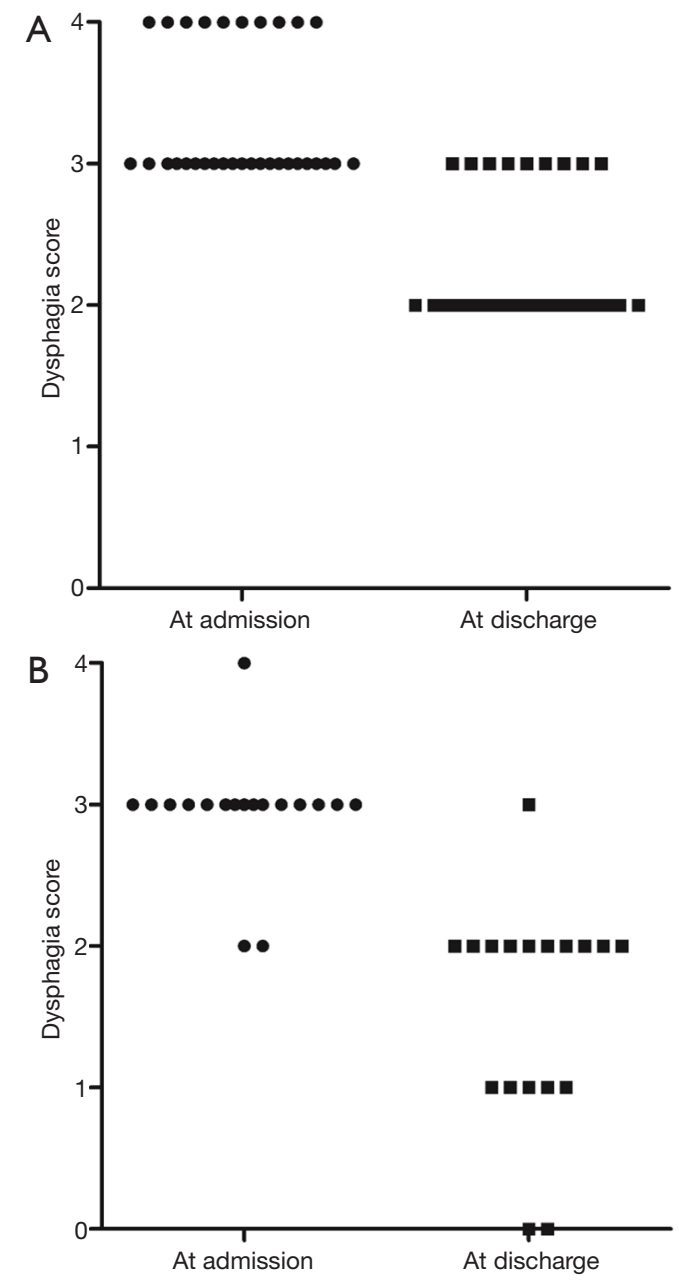

Figure 1 Improvement of dysphagia scores after ESP (A) and EIM (B). ESP, esophageal stent placement; EIM, endoscopic incision method.

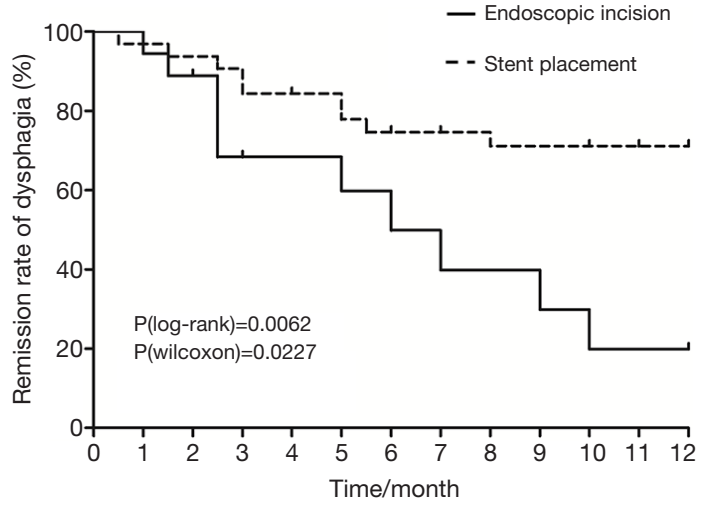

Figure 2 Comparison of remission rates of dysphagia between ESP and EIM. ESP, esophageal stent placement; EIM, endoscopic incision method.

are summarized in Figure 1. Notably, the dysphagia scores of all patients in the ESP group improved by 1 point. Some patients in the EIM group improved by 2 points, but none improved by 3 points. The diameter of dilatation in each group is shown in Table 2. Patients in the ESP group had a markedly larger diameter of dilatation than those in the EIM group $(19.9 \pm 1.8$ versus $11.0 \pm 1.9 \mathrm{~mm}$, respectively; $\mathrm{P}<0.001)$.

We recorded the time of hospital readmission for dysphagia during the follow-up period. In nearly all patients who were readmitted, readmission occurred within 12 months of the procedure, except two patients in the EIM group who were readmitted within 20 months of the procedure. The 12-month dysphagia remission rates in the two groups are shown in Figure 2. According to logrank and Wilcoxon analyses, the ESP group had a much higher remission rate than the EIM group $(\mathrm{P}=0.0062$ and $\mathrm{P}=0.0227$, respectively).

\section{Safety of procedures}

Table 3 shows details of the safety of the two procedures. The median hospital stay in the ESP group was longer than that in the EIM group $(9.0 \pm 4.8$ versus $6.0 \pm 1.9$ days, respectively; $\mathrm{P}=0.022)$. No patient in either group had perforation. Five patients experienced mild bleeding (four in ESP group versus one in EIM group); no severe bleeding requiring blood transfusion occurred. Thirteen patients in the ESP group experienced mild chest pain; seven of these patients required a painkiller. Pain was relieved by the medication within a few days. 
Table 3 safety of procedures

\begin{tabular}{lccc}
\hline Variables & $\begin{array}{c}\text { Stent group } \\
\text { (32 cases) }\end{array}$ & $\begin{array}{c}\text { Incision group } \\
(\mathrm{n}=18 \text { cases })\end{array}$ & $\mathrm{P}$ value \\
\hline Length of hospital stay & $9.0 \pm 4.8$ & $6.0 \pm 1.9$ & 0.022 \\
$\begin{array}{l}\text { Adverse events } \\
\text { Perforation }\end{array}$ & 0 & 0 & - \\
$\begin{array}{l}\text { Slight bleeding } \\
\text { Severe bleeding requiring } \\
\text { blood transfusion }\end{array}$ & 0 & 1 & 0.413 \\
$\begin{array}{l}\text { Infection } \\
\text { Slight retrosternal pain }\end{array}$ & 13 & 0 & - \\
$\begin{array}{l}\text { Severe pain requiring } \\
\text { painkiller drug }\end{array}$ & 7 & 0 & $<0.001$ \\
\hline
\end{tabular}

\section{Discussion}

Most esophageal anastomotic strictures are refractory to repeated endoscopic dilatation. ESP and EIM were developed to achieve sustained symptomatic improvement and maintain a wide lumen in patients with refractory esophageal anastomotic stricture. However, little is known about differences between ESP and EIM in these patients. In this retrospective study, we collected clinical data of patients with refractory esophageal anastomotic stricture to compare the efficacy and safety of the two procedures. The results indicate that both procedures effectively relieved symptoms of dysphagia and that the incidence of adverse events after both procedures was low. However, the duration of remission of esophageal anastomotic stricture after ESP was longer than that after EIM. This study provides clinical evidence for the treatment of refractory esophageal anastomotic stricture.

The primary outcome in our study was dysphagia score of included patients; patients in both groups had significant relief of stricture. The dysphagia scores at both admission and discharge were higher in the ESP group than in the EIM group; the dysphagia score dropped more in the EIM group than in the ESP group. We found some explanations for these results during follow-up. Most patients who underwent ESP experienced chest pain that worsened during eating for days after the procedure. This pain kept patients from eating solid food despite greater esophageal dilatation. In contrast, most patients were able to eat solid food after EIM because they had less pain and discomfort, although the diameter of dilatation in the EIM group was smaller than that in the
ESP group. Furthermore, patients in the ESP group had a lower BMI and lower serum albumin than those in the EIM group. These findings indicate that patients in the ESP group had malnutrition, primarily because of longer duration of esophageal anastomotic stricture and smaller diameter of stricture. Malnutrition may induce impaired gastrointestinal function and gastrointestinal intolerance, which can affect the efficacy of ESP.

Dan $e t a l$. defined clinical success of ESP as the sustained relief of dysphagia for at least 6 months after initial stent removal (19). The definition of short-term efficacy of EIM is improvement in dysphagia in the first 6 months after the procedure and long-term efficacy is improvement in the first 12 months $(13,15)$. In our study nearly $70 \%$ of patients maintained lumen patency for 12 months after ESP, a result similar to a previous study (20). The main problem in treating esophageal anastomotic strictures with ESP is the high cost of the procedure $(8,21,22)$. In contrast, only $50 \%$ of patients had sustained relief of stricture symptoms at 6 months after EIM and only $20 \%$ had relief at 12 months. Unlike the strictures associated with malignant disease, anastomotic strictures are usually caused by fibrosis (6). Intralesional steroid injection after EIM was reported to reduce the risk of recurrent fibrosis. We previously found that intramuscular injection of mitomycin $\mathrm{C}$ combined with endoscopic dilatation clearly extended the dysphagia-free duration in patients with benign esophageal strictures (23). However, mitomycin $\mathrm{C}$ did not show significant efficacy in EIM treatment. The optimal injection technique, frequency of injection and dose of injectable corticosteroids should be further explored (15).

EIM is usually performed without injection because scar tissue at the anastomotic site adheres tightly to the muscularis propria, preventing injection into the site and making the procedure risky. However, only one patient who underwent EIM in our study experienced hemorrhage and none needed blood transfusion. This result may be partly attributed to the fact that enrolled patients had been admitted to our hospital several times and operating doctors were familiar with their condition. In addition, the length of stricture in the EIM group was shorter than $3 \mathrm{~cm}$, making it easy and safe to create incisions with the IT knife (13).

The most common complaint of patients in the ESP group was chest pain. The incidence of chest pain was higher among patients with upper esophageal stricture than among those with stricture at other esophageal sites $(24,25)$. The reported rates of chest pain range from $11 \%$ to $80 \%$, with most patients not needing painkillers (26). In 
our study, 20 patients experienced chest pain after ESP and seven of these required painkillers; all seven had strictures located in the upper esophagus. The probable cause of the pain was expansion of the esophageal wall after stent expansion and esophageal spasm secondary to gastric acid reflux (27). Moreover, the degree of chest pain was related to the diameter of strictures and stents. Chinese and other Asian patients with esophageal anastomotic stricture generally prefer stents of suitable size to minimize chest pain, whereas Western patients prefer larger stents to allow ingestion of solid food; therefore, the type of stent and duration of stenting should be individualized $(20,28)$. After discharge, chest pain decreased gradually and most patients resumed a normal diet.

The European Society of Gastrointestinal Endoscopy recommends covered stents for the treatment of stricture because they do not become embedded and are thus easy to remove (8). However, the reported migration rate is up to $32 \%$, especially when the stent is placed near the cardia $(27,29)$. In our study, no patient experienced stent migration. We usually choose partially covered stents to increase friction between the stent and the esophageal wall and we anchor the lower end of stent to the esophagus (27). No significant adverse events (bleeding, perforation or fistula) were observed in our study during stent placement or during the removal procedure.

This study had some limitations. First, it was a retrospective analysis of the efficacy of ESP and EIM at a single center. The small sample size restricted further analysis; a study with more patients is needed to confirm our results. Second, the dysphagia score was recorded only at admission and at discharge; more quantitative indicators are needed to evaluate the treatment effects during the follow-up period.

Our study demonstrated that EIM can rapidly reduce the dysphagia score and relieve symptoms but that ESP provided longer duration of relief. Both procedures are safe for patients and no severe adverse events were observed in this study. Because of the limitations of a retrospective study, larger comparative studies on this subject are needed.

\section{Acknowledgments}

We thank Rebecca Tollefson, DVM, from Liwen Bianji, Edanz Editing China (www.liwenbianji.cn/ac), for editing the English text of a draft of this manuscript.

\section{Footnote}

Conflicts of Interest: The authors have no conflicts of interest to declare.

Ethical Statement: The authors are accountable for all aspects of the work in ensuring that questions related to the accuracy or integrity of any part of the work are appropriately investigated and resolved. This study was performed in compliance with the ethical principles of the Declaration of Helsinki and was approved by the Ethics Committee of Second Affiliated Hospital of Nanjing Medical University [(2019)KY085]. Because of the retrospective nature of the study, written informed consent was not obtained from the patients.

\section{References}

1. Enzinger PC, Mayer RJ. Esophageal cancer. New Engl J Med 2003;349:2241-52.

2. Tanaka Y, Yoshida K, Suetsugu T, et al. Recent advancements in esophageal cancer treatment in Japan. Ann Gastroenterol Surg 2018;2:253-65.

3. Sundelöf $M$, Ye W, Dickman PW, et al. Improved survival in both histologic types of oesophageal cancer in Sweden. Int J Cancer 2002;99:751-4.

4. Briel JW, Tamhankar AP, Hagen JA, et al. Prevalence and risk factors for ischemia, leak, and stricture of esophageal anastomosis: gastric pull-up versus colon interposition. J Am Coll Surg 2004;198:536-41; discussion 541-2.

5. Rice TW. Anastomotic stricture complicating esophagectomy. Thorac Surg Clin 2006;16:63-73.

6. van Heijl M, Gooszen JA, Fockens P, et al. Risk factors for development of benign cervical strictures after esophagectomy. Ann Surg 2010;251:1064-9.

7. ASGE Standards of Practice Committee, Pasha SF, Acosta RD, et al. The role of endoscopy in the evaluation and management of dysphagia. Gastrointest Endosc 2014;79:191-201.

8. Spaander MC, Baron TH, Siersema PD, et al. Esophageal stenting for benign and malignant disease: European Society of Gastrointestinal Endoscopy (ESGE) Clinical Guideline. Endoscopy 2016;48:939-48.

9. Minamino H, Machida H, Tominaga K, et al. Endoscopic radial incision and cutting method for refractory esophageal stricture after endoscopic submucosal dissection of superficial esophageal carcinoma. Dig Endosc 2013;25:200-3.

10. Fuccio L, Hassan C, Frazzoni L, et al. Clinical outcomes following stent placement in refractory benign esophageal stricture: a systematic review and meta-analysis. Endoscopy 
2016;48:141-8.

11. Burdick JS, Venu RP, Hogan WJ. Cutting the defiant lower esophageal ring. Gastrointest Endosc 1993;39:616-9.

12. DiSario JA, Pedersen PJ, Bichis-Canoutas C, et al. Incision of recurrent distal esophageal (Schatzki) ring after dilation. Gastrointest Endosc 2002;56:244-8.

13. Muto M, Ezoe Y, Yano T, et al. Usefulness of endoscopic radial incision and cutting method for refractory esophagogastric anastomotic stricture (with video). Gastrointest Endosc 2012;75:965-72.

14. Tan Y, Wang X, Lv L, et al. Comparison of endoscopic incision and endoscopic balloon dilation for the treatment of refractory colorectal anastomotic strictures. Int J Colorectal Dis. 2016;31:1401-3.

15. Tan Y, Liu D. Endoscopic incision for the treatment of refractory esophageal anastomotic strictures: outcomes of 13 cases with a minimum follow-up of 12 months. Rev Esp Enferm Dig 2016;108:196-200.

16. Jain D, Sandhu N, Singhal S. Endoscopic electrocautery incision therapy for benign lower gastrointestinal tract anastomotic strictures. Ann Gastroenterol 2017;30:473-85.

17. Hordijk ML, Siersema PD, Tilanus HW, et al. Electrocautery therapy for refractory anastomotic strictures of the esophagus. Gastrointest Endosc 2006;63:157-63.

18. Kochman ML, McClave SA, Boyce HW. The refractory and the recurrent esophageal stricture: a definition. Gastrointest Endosc 2005;62:474-5.

19. Dan DT, Gannavarapu B, Lee JG, et al. Removable esophageal stents have poor efficacy for the treatment of refractory benign esophageal strictures (RBES). Dis Esophagus 2014;27:511-7.

20. Yano T, Yoda Y, Nomura S, et al. Prospective trial of biodegradable stents for refractory benign esophageal

Cite this article as: $\mathrm{Wu} \mathrm{P}$, Wang $\mathrm{F}, \mathrm{Wu} \mathrm{X}$, Nie J, Ge $\mathrm{X}, \mathrm{Li}$ Q, Lin J, Miao L. Comparison of esophageal stent placement versus endoscopic incision method for treatment of refractory esophageal anastomotic stricture. Ann Palliat Med 2019;8(4):462-468. doi: 10.21037/apm.2019.09.07 strictures after curative treatment of esophageal cancer. Gastrointest Endosc 2017;86:492-9.

21. Shenfine J, McNamee P, Steen N, et al. A pragmatic randomised controlled trial of the cost-effectiveness of palliative therapies for patients with inoperable oesophageal cancer. Health Technol Assess 2005;9:iii, 1-121.

22. Dumonceau JM, Cremer M, Lalmand B, et al. Esophageal fistula sealing: choice of stent, practical management, and cost. Gastrointest Endosc 1999;49:70-8.

23. Zhang $\mathrm{Y}$, Wang $\mathrm{X}$, Liu L, et al. Intramuscular injection of mitomycin $\mathrm{C}$ combined with endoscopic dilation for benign esophageal strictures. J Dig Dis 2015;16:370-6.

24. Kawasaki R, Sano A, Matsumoto S. Long-term outcomes and complications of metallic stents for malignant esophageal stenoses. Kobe J Med Sci 2003;49:133-42.

25. Sarper A, Oz N, Cihangir C, et al. The efficacy of selfexpanding metal stents for palliation of malignant esophageal strictures and fistulas. Eur J Cardiothorac Surg 2003;23:794-8.

26. Acunaş B, Rozanes I, Akpinar S, et al. Palliation of malignant esophageal strictures with self-expanding nitinol stents: drawbacks and complications. Radiology 1996;199:648-52.

27. Turkyilmaz A, Eroglu A, Aydin Y, et al. Complications of metallic stent placement in malignant esophageal stricture and their management. Surg Laparosc Endosc Percutan Tech 2010;20:10-5.

28. Sabharwal T, Morales JP, Irani FG, et al. Quality improvement guidelines for placement of esophageal stents. Cardiovasc Intervent Radiol 2005;28:284-8.

29. Thomas T, Abrams KR, Subramanian V, et al. Esophageal stents for benign refractory strictures: a meta-analysis. Endoscopy 2011;43:386-93. 